PNL-SA-25908

\title{
ULTRA WIDE BAND RADAR HOLOGRAPHIC IMAGING OF BURIED WASTE AT DOE SITES
}

H. D. Collins

R. P. Gribble

T. E. Hall

W. M. Lechelt

April 1995

Presented at the

1995 Symposium on the Application of Geophysics to

Engineering \& Environmental Problems

April 24-26, 1995

Orlando, Florida

Prepared for

the U.S. Department of Energy

under Contract DE-AC06-76RLO 1830

Pacific Northwest Laboratory

Richland, Washington 99352

\section{DISCLAIMER}

This report was prepared as an account of work sponsored by an agency of the United States Government. Neither the United States Government nor any agency thereof, nor any of their employees, makes any warranty, express or implied, or assumes any legal liability or responsibility for the accuracy, completeness, or usefulness of any information, apparatus, product, or process disclosed, or represents that its use would not infringe privately owned rights. Reference herein to any specific commercial product, process, or service by trade name, trademark, manufacturer, or otherwise does not necessarily constitute or imply its endorsement, recommendation, or favoring by the United States Government or any agency thereof. The views and opinions of authors expressed herein do not necessarily state or reflect those of the United States Government or any agency thereof. 


\section{DISCLAIMER}

Portions of this document may be illegible in electronic image products. Images are produced from the best available original document. 


\title{
ULTRA WIDE BAND RADAR HOLOGRAPHIC IMAGING OF BURIED WASTE AT DOE SITES
}

\author{
H. D. Collins, R. P. Gribble, T. E. Hall, and W. M. Lecheit \\ Pacific Northwest Laboratory 1 \\ P. O. Box 999 \\ Richland, WA 99352
}

\begin{abstract}
Ultra wideband linear array holography is a unique real-time imaging technique for in-situ inspection of buried waste at various DOE sites. The array can be mounted on various platforms such as crane booms, pickup trucks, ATVs, and scanned generating " $3-\mathrm{D}$ " subsurface images in real time. Inspection speeds are approximately 0.5 to 2 meters/sec, if the image is viewed in real time, greater for off-line processing.

The Ground Penetrating Holographic (GPH) system developed for inspection of DOE sites employs two 32element arrays of tapered-slot antenna operating at $5-\mathrm{GHz}$ and $2.5-\mathrm{GHz}$ center frequencies. The GPH system, which is mounted on a small trailer with a computer image processor, display, and power supply, is capable of imaging a wide swath (1 to 2 meters) with its linear arrays. The lower frequency array will be used at INEL (for greater depth penetration) because of high soil attenuation.

Recent holographic "3-D" images of buried waste container lids and dielectrics obtained in Hanford sand and INEL soils at various depths graphically illustrate the unique image resolution capabilities of the system.

Experimental results using the 5- $\mathrm{GHz}$ array will be presented showing the excellent holographic image quality of various subsurface targets in sand and INEL soil.
\end{abstract}

\section{INTRODUCTION}

Holographic Impulse Theory

Ultra wideband (UWB) linear array radar holography is a unique "real-time" imaging technique for imaging buried waste with extremely high lateral and depth resolution. The large frequency bandwidth, typically $100 \%$, provides excellent depth resolution and the synthetic aperture optimum lateral resolution of one-half wavelength at the center pulse frequency.

The ground penetrating UWB holographic (GPH) system generates high-resolution "3-D" images of buried waste in real time using the most advanced linear array technology. The linear array is attached to a motor vehicle above the surface (air-coupled). It is then scanned over the buried waste, and " $3-\mathrm{D}$ " images are generated in real time.

The array is approximately 1 meter in length, producing an image of approximately this width in one scan of the vehicle. The images are scrolled continuously in length as the vehicle scans over the terrain. Large areas can be inspected in a relatively short time compared with conventional ground penetrating radar (single-channel) systems with the linear array.

Let us consider a near-field scanned aperture UWB radar system. The received impulse signal can be expressed as a time-shifted waveform in terms of the target's range and propagation velocity of the medium.

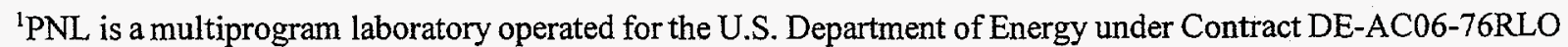
1830 by Battelle Memorial Institute. 


$$
h\left(t-t_{T}\right)=h\left(t-\frac{2 r_{T}}{c}\right)
$$

After recording the time-shifted impulse waveforms over the entire aperture, we compute the Fourier transform of each waveform, which decomposes them into their discrete frequency components. These components are simply the holographic signals for each frequency in the impulse and can be expressed by the following equation.

$$
F T\left[h\left(t-\frac{2 r_{T}}{c}\right)\right]=H(x, y, f) e^{-j \phi_{T}\left(x, y_{j} f\right)}
$$

where

$$
\begin{aligned}
r_{T}=r(x, y)=\sqrt{\left(x-x_{1}\right)^{2}+\left(y-y_{1}\right)^{2}+z_{1}^{2}} & =\text { distance to target } \\
\Phi_{T}\left(x, y_{2}\right)=\frac{4 \pi r(x, y)}{\lambda} & =\text { phase of target at frequency (f) } \\
H\left(x, y_{1} f\right) & =\text { target amplitude at frequency (f) } \\
\lambda & =\text { wavelength at frequency (f). }
\end{aligned}
$$

Equation (2) can be written in terms of its real $U_{r}$ and imaginary Ui components for all frequencies in the pulse.

$$
U_{R}\left(x, y_{2} f\right)=H(x, y, f) \cos \left(\frac{4 \pi r_{T}}{\lambda}\right)
$$

and

$$
U_{i}\left(x, y_{2} f\right)=H\left(x, y_{2} f\right) \sin \left(\frac{4 \pi r_{T}}{\lambda}\right)
$$

These expressions are very familiar to radar holographic engineers. They are the holographic signals for each frequency component in the impulse, and they completely describe the target's reflectivity $H\left(x, y_{2}\right)$ and the phase $\left(\frac{4 \pi r_{T}}{\lambda}\right)$. They can be computed from the following equations.

$$
\begin{gathered}
H(x, y, f)=\sqrt{U_{R}^{2}(x, y, f)+U_{I}^{2}(x, y, f)} \\
\phi_{T}\left(x, y_{2} f\right)=\frac{4 \pi r_{T}}{\lambda}=\tan ^{-1}\left[\frac{U_{I}\left(x, y_{2} f\right)}{U_{R}\left(x, y_{2} f\right)}\right]
\end{gathered}
$$

\section{Computer Reconstruction of Impulse Data}

Assume the radar holographic system operates in a mono-static mode and the UWB signal received at the scanned aperture is expressed by the following equation:

$$
s\left(x^{\prime}, y^{\prime}, o, f\right)=\iint f_{T}(x, y, z, f) e^{j 2 k R} d x d y
$$


where $f_{\mathrm{T}}(\mathrm{x}, \mathrm{y}, \mathrm{z}) \quad=$ target reflectivity

$\mathrm{k}=$ the wave number

$\mathrm{x}, \mathrm{y}, \mathrm{z}=$ target coordinates

$\mathrm{x}^{\prime}, \mathrm{y}^{\prime}, \mathrm{o}=$ receiver coordinates

$\mathrm{R}=$ distance to target $=\sqrt{\left(x^{\prime}-x\right)^{2}+\left(y^{\prime}-y\right)^{2}+z^{2}}$

$\mathrm{e}^{\mathrm{j} 2 \mathrm{kR}}=$ spherical wave $=\iint e^{j k_{x}\left(x^{\prime}-x\right)+j k_{y}\left(y^{\prime}-y\right)+j k_{z}(0-z)} d k_{x}^{\prime} d k_{y}^{\prime}$

The spherical wave can be expressed as a vector summation of plane waves. If we substitute this expression into Equation (7), the received signal is given by the following equation.

$$
s(x, y, o, f)=\iint\left\{\int f_{T}(x, y, z, f) e^{-j\left(k_{x} x+k_{y}\right)} d x d y\right\} e^{j\left(x_{x}^{\prime}+k_{y} y\right)} e^{j k_{z}^{R}} d k_{x}^{\prime} d k_{y}^{\prime}
$$

The term in brackets is the target's plane wave angular spectrum (i.e., Fourier transform of target's activity). We can express it by the following equation.

$$
A_{T}\left(k_{x}, k_{y}, z_{2} f\right)=\iint f_{T}\left(x, y, z_{2} f\right) e^{-j\left(k_{x} x+k_{y}, y\right)} d x d y
$$

We can then write Equation (7) as

$$
\begin{aligned}
s\left(x^{\prime}, y^{\prime}, o_{y} f\right) & =\iint A_{X}\left(k_{x}, k_{y}, z_{y} f\right) e^{j\left(k_{x}, x^{\prime}+k_{y}, y\right)} e^{-j k_{z} z} d k_{x} d k_{y^{\prime}} \\
& =F T^{-1}\left[A_{\lambda}\left(k_{x}, k_{y}, z_{z} f\right) e^{-j k_{z} R}\right]
\end{aligned}
$$

The result of taking the Fourier transform (both sides) of Equation (11) is

$$
F T\left[S\left(x^{\prime}, y^{\prime}, o, f\right]=A_{7}\left(k_{x}, k_{y}, z_{y}\right) e^{-j k_{z}^{\prime z}}=A_{d}\left(k_{x^{\prime}}, k_{y}^{\prime}, o_{y} f\right)\right.
$$

This expression uniquely defines the target's angular spectrum in terms of the angular spectrum computed from the recorded aperture data $s\left(x^{\prime}, y^{\prime}, 0, f\right)$ and the back propagation factor $e^{j k_{z} / z}$.

$$
A_{\eta}\left(k_{x}, k_{y}, f_{j}\right)=\sum A_{d}\left(k_{x^{\prime},} k_{y}, o, f\right) e^{j k_{x} / z}
$$

UWB Holographic Image

The UWB image of the target is simply the absolute value of the inverse Fourier transform of its multi-frequency angular spectrum.

$$
I M A G E=f_{T}(x, y, z, f)=F T^{-1}\left[A_{T}\left(k_{x}, k_{y}, z_{y} f\right)\right]=F T^{-1}\left[\sum A_{0}\left(k_{x^{\prime}}, k_{y}, o, f\right) e^{j k_{z} z}\right]
$$

where $k_{z^{\prime}}=\sqrt{4 k^{2}-\left(k_{x}\right)^{2}-\left(k_{y}\right)^{2}}$ 


\section{EXPERIMENTAL RESULTS}

A 5-GHz center frequency UWB impulse with a $100 \%$ bandwidth radar system was used to construct holographic images of shallow subsurface targets in INEL and dry sand soils. The targets simulated small circular waste canisters (metal and dielectric), and varied in diameter from $10 \mathrm{~cm}$ to $22 \mathrm{~cm}$, and were buried at a depth of approximately 1 meter. The metal letter "F" is approximately $30 \mathrm{~cm}$ in width and $52 \mathrm{~cm}$ in length and is used as a resolution target.

Figure 1 is the holographic image and "3-D" amplitude profile of the letter "F" and three simulated canisters buried approximately 1 meter in Hanford sand. The images are of excellent quality and graphically illustrate the resolution capabilities of the system.

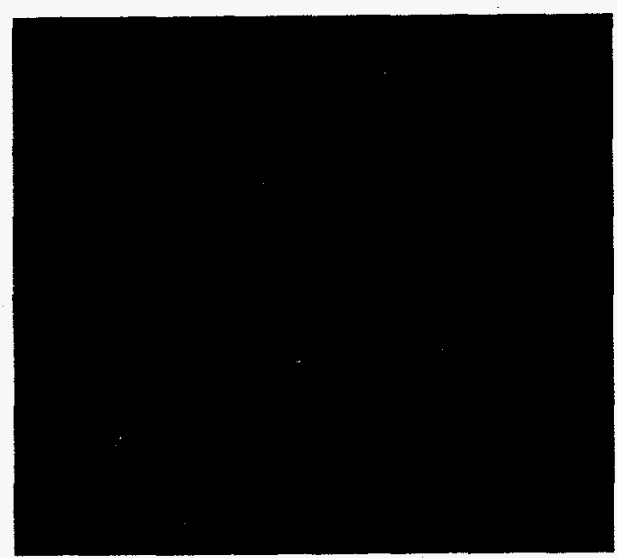

(a)

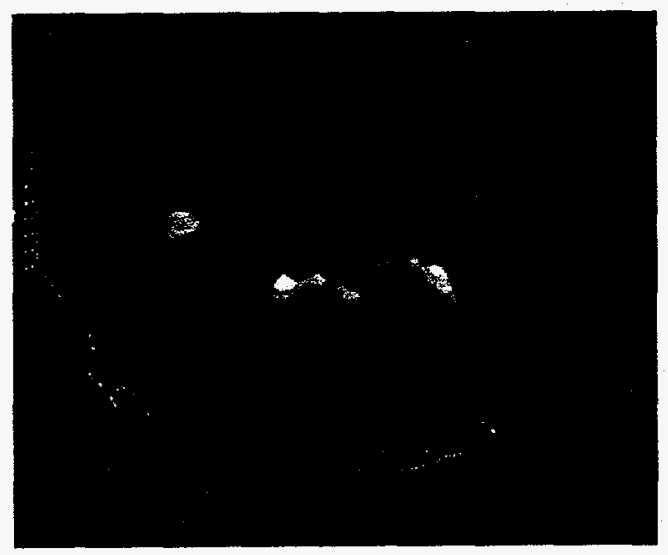

(b)

Figure 1. Holographic Images of Buried Targets (1 meter in sand): (a) top view and (b) intensity "3-D" view

Figure 2 is a picture of the UWB holographic $5-\mathrm{GHz}$ linear array buried waste imaging system mounted on a small trailer for DOE/BWID project at Idaho Falls.

Figure 3 is the holographic image of a 55 -gallon drum lid buried approximately $20 \mathrm{~cm}$ in INEL soil.

\section{CONCLUSIONS}

Real-time UWB holographic linear array imaging is a viable technique for imaging subsurface targets in low conductivity soils. The center frequency and bandwidth of the impulse should be selected with respect to soil penetration depth (target range), radar cross section, and size of targets to be imaged.

One of the most important soil attenuation factors appears to be moisture content, and successful surveys with radar must include selecting the optimum penetration frequency. In our experiments, we used a 5-GHz center frequency linear array (1 meter in length) with a $100 \%$ bandwidth for imaging small targets $(10 \mathrm{~cm}$ to $52 \mathrm{~cm})$ both metal and dielectric at penetration depths between the surface and 1 meter depth in dry sand. A 2.5-GHz linear array (meters in length) is under construction and will be used in imaging shallow buried waste at a INEL/BWID demonstration this year. 


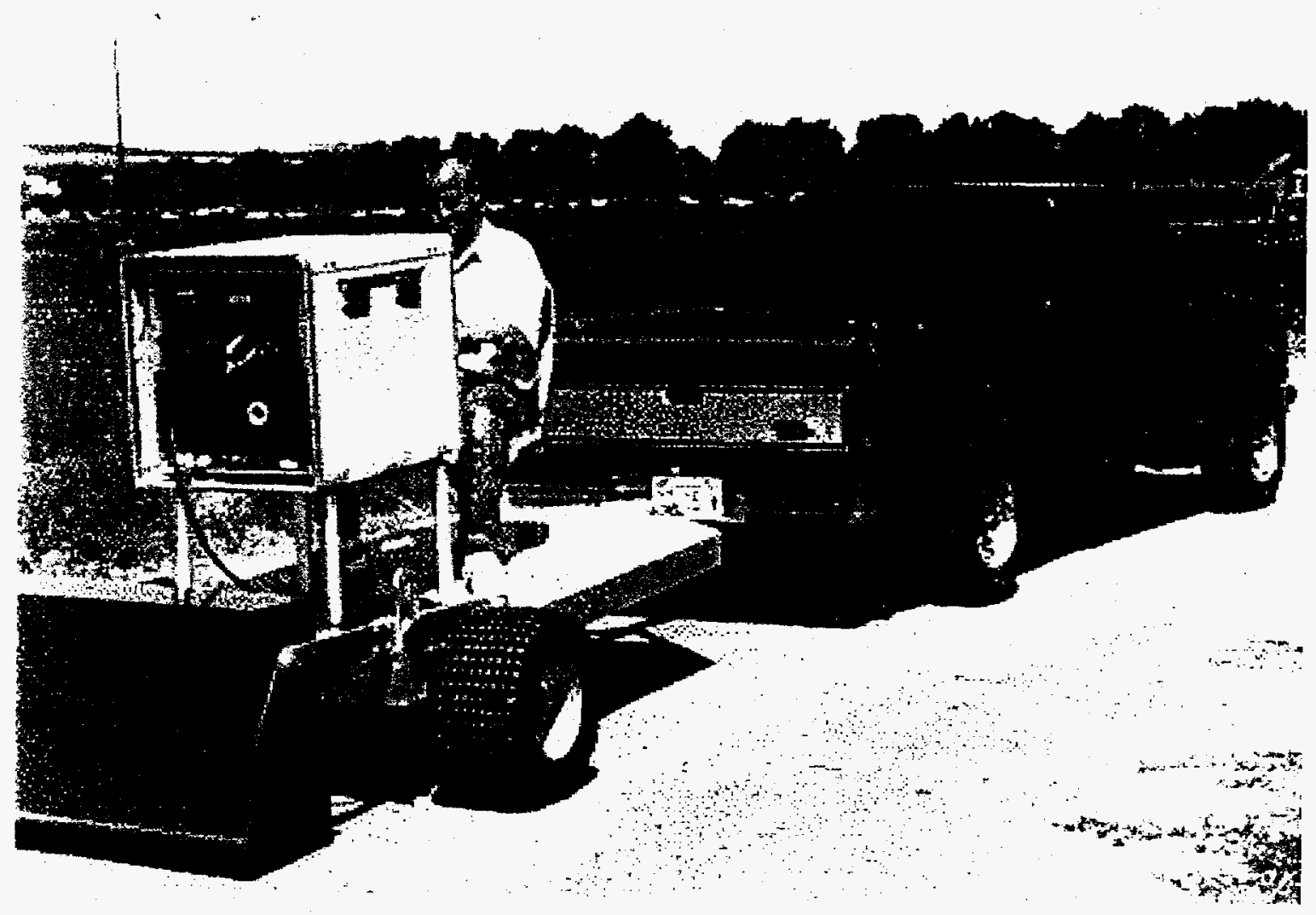

Figure 2. Holographic Array System on Trailer
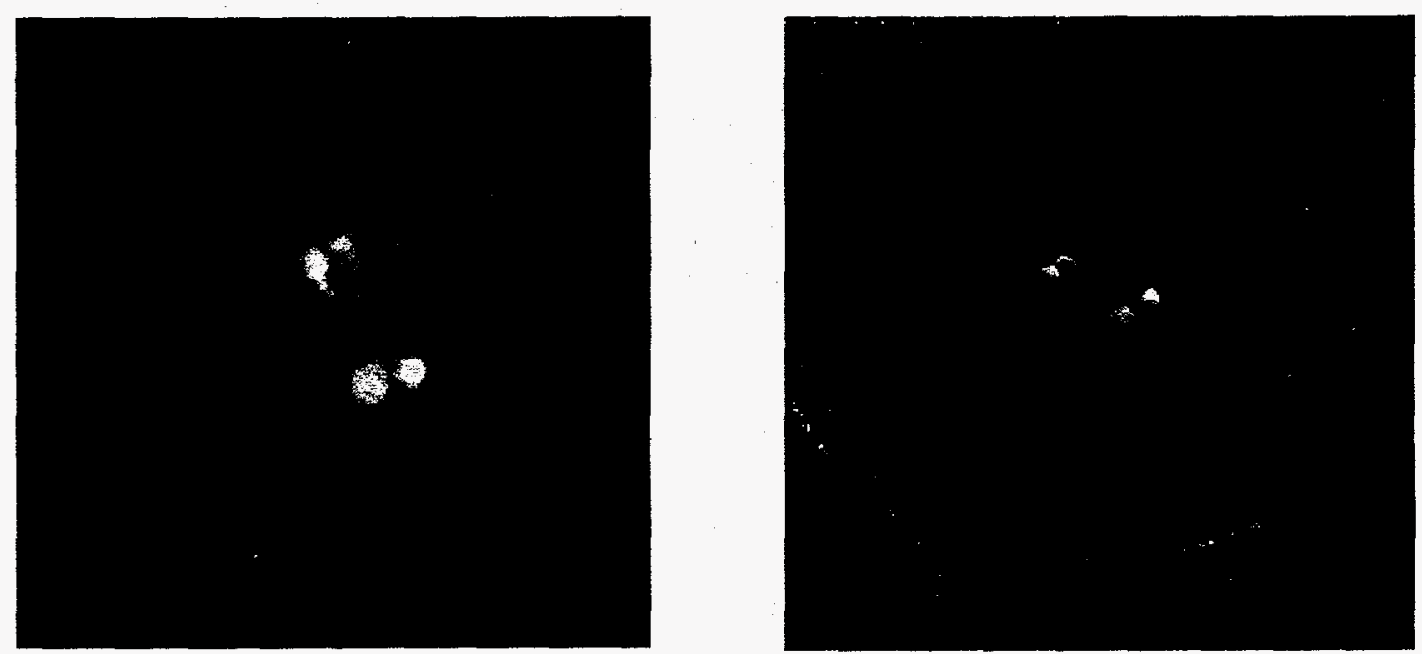

Figure 3. Holographic Image of Waste Drum Lid 